\title{
Obtenção biotecnológica de xilitol a partir da casca de mandioca (Manihot esculenta)
}

\author{
Talessa Neves Pereira ${ }^{a^{*}}$, Aline Aires Aguiar ${ }^{\mathrm{b}}$, Ernane Bastos Gerre ${ }^{\mathrm{a}^{*}(\mathbb{C}}$ \\ ${ }^{a}$ Universidade Luterana de Palmas, Brasil \\ ${ }^{\mathrm{b}}$ Instituto Tocantinense Presidente Antônio Carlos, Brasil \\ *Autor correspondente (talessa.np@gmail.com)
}

\section{N F O \\ Keywords \\ cassava \\ fermentation \\ xytlitol}

\begin{abstract}
A B S T R A C T
Biotechnological obtaining of xylitol from cassava (Manihot esculenta)

Xylitol is a sweetener with several human health benefits like the anti cariogenicity and no need insulin for the metabolism therefore, it can be consumed by diabetics, it can be obtained in three ways: extraction, chemical or biotechnological production. To obtain xylitol chemically or biotechnologically it is necessary to use materials containing cellulose and hemicellulose, because it is from the hydrolysis of these compounds that xylose is released and then reduced to xylitol. The objective of this work was to obtain xylitol from the xylose present in the cassava peel through the biotechnological way. For this, the peel went through preparation processes before fermentation, such as sanitization, drying, grinding and hydrolysis, and then the fermentation was done with the use of Candida albicans yeast. The xylose concentration obtained by the methodology used was $0.27 \mathrm{~g} / \mathrm{L}$, besides this sugar it was obtained $2.16 \mathrm{~g} / \mathrm{L}$ of cellobiose, $0.18 \mathrm{~g} / \mathrm{L}$ of glucose and $0.29 \mathrm{~g} / \mathrm{L}$ of arabnose. At the fermentation stage, the concentration of some products was not detected by the liquid chromatography reader. Therefore, the cassava bark has fermentable sugars that can be used to obtain products, so their disposal is not the only targeting option for this byproduct.
\end{abstract}

\section{R E S U M O}

O xilitol é um edulcorante com diversos benefícios para a saúde humana, como a anti cariogenicidade e a não necessidade de insulina para metabolização, portanto ele pode ser consumido por diabéticos, ele pode ser obtido de três formas: extração, produção por processo químico ou biotecnológico. Para obter o xilitol por via química ou biotecnológica é necessária a utilização de materiais que contenham celulose e hemicelulose, pois é a partir da hidrólise desses compostos que a xilose é liberada e depois reduzida a xilitol. Desta forma, esse trabalho teve como objetivo obtenção de xilitol a partir da xilose presente na casca de mandioca através da via biotecnológica, para isso a casca passou por processos de preparação antes da fermentação, como higienização, secagem, trituração e hidrólise, e então foi feita a fermentação com a utilização da levedura Candida albicans. A concentração de xilose obtida através da metodologia utilizada foi de 0,27 g/L, além desse açúcar obteve-se 2,16 g/L de celobiose, $0,18 \mathrm{~g} / \mathrm{L}$ de glicose e $0,29 \mathrm{~g} / \mathrm{L}$ de arabnose, já na etapa da fermentação a concentração de alguns produtos não foi detectada pelo leitor de cromatografia líquida. Portanto a casca mandioca possui açúcares fermentescíveis que podem ser utilizados na obtenção de produtos, sendo assim o seu descarte não é a única opção de direcionamento para esse subproduto. 


\section{INTRODUÇÃO}

O açúcar é um edulcorante amplamente utilizado em diversos alimentos pois adiciona um diferencial que torna o alimento rico em energia e sabor. A sacarose é o açúcar mais adicionado aos alimentos, em excesso provoca diversos malefícios, como doenças dentárias, obesidade e diabetes. Portanto, a indústria procura por adoçantes alternativos que se pareçam com a sacarose em questão de sabor e reduza seus efeitos adversos (Riley et al., 2011).

Uma das alternativas encontradas foi o xilitol. Um poliol que possui o mesmo potencial adoçante da sacarose, entretanto, com alguns pontos diferenciais, por exemplo, não precisa da insulina para ser metabolizado, sendo indicado para diabéticos, possui menos calorias e é anticariogênico, essas são algumas das principais propriedades que tornam seu consumo vantajoso (Kumar, 2019).

O xilitol é um açúcar benéfico, com aplicações na farmacêutica devido a sua elevada atividade antibiótica, a qual é caracterizada por gêneros bacterianos incapazes de metabolizar o xilitol e utilizálo como fonte de energia, portanto esses microrganismos encontram poucos meios de sobrevivência quando o indivíduo se alimenta com xilitol, sendo assim ele ajuda a proteger não somente os dentes, mas também outras partes do organismo como pulmão, ouvidos e derme (Dasgupta, 2017).

Esse edulcorante é obtido a partir de materiais ligno-celulósicos, que quando passam por um processo de hidrólise, liberam a xilose, matéria prima inicial para a produção do xilitol. Existem três formas de se obter o xilitol, a extração que não é mais praticada por ser pouco vantajosa, e as formas biotecnológica e química enzimática, ambas precisam de um material lignocelulósico como matéria prima (Yewale et al., 2017). A hidrólise enzimática, utiliza a enzima xilose redutase para reduzir a xilose a xilitol e a fermentação utiliza as leveduras que possuem essa enzima (Ur-Rheman, 2015).

O processo mais vantajoso é a via biotecnológica pois possui baixo custo, utilização de poucos maquinários, não necessidade de condições de temperatura e pressão extremas, a presença das enzimas necessárias naturalmente nas leveduras, a qual é responsável por uma das principais vantagens já que a produção artificial dessas enzimas gera muitos resíduos poluentes (De Souza, 2019).

Portanto esse trabalho tem como objetivo utilizar a casca de mandioca para a obtenção de xilitol já que é composta por material lignocelulósico. Apesar da mandioca ser bastante consumida, a sua casca, que é $8 \%$ da composição da raiz, na maioria das vezes, é descartada (Dourado et al., 2017). No Brasil no ano de 2016 foram produzidas mais de 23,6 milhões toneladas de mandioca de acordo com De Brito et al. (2019), portanto somente no Brasil a geração de resíduos a partir desse produto é bastante alta. E esse subproduto, que seria descartado pode ter valor sendo utilizado para obter o xilitol, um produto de interesse para as indústrias farmacêutica, odontológica e alimentícia.

\section{MATERIAL E MÉTODOS}

\section{Pré-tratamento da matéria prima}

A metodologia utilizada foi adaptada a partir da metodologia utilizada por Arruda et al. (2008). Foram coletados $300 \mathrm{~g}$ de casca de mandioca vendida em um supermercado da cidade de Palmas, as quais foram lavadas em água corrente 3 vezes e após a lavagem ela foi secada durante 3 dias em ambiente seco e com pouca ventilação, posteriormente ela foi triturada.

Após o tratamento inicial realizou-se a etapa de hidrólise. O hidrolisado foi obtido a partir da hidrólise ácida na casca, onde foram utilizadas 10 gramas de matéria prima em $100 \mathrm{~mL}$ de ácido Sulfúrico a $1 \mathrm{~mol} / \mathrm{L}$, a casca ficou emergida no ácido durante 24 horas em agitação constante a 150 RPM em um agitador magnético modelo 753A temperatura ambiente. Após as 24 horas, foram adicionados $2,4 \%$ de carvão ativado ao hidrolisado, em seguida ele foi colocado em uma centrífuga modelo $80-2 b$ durante 30 minutos à uma rotação de 2500 RPM.

Então, o pH da solução foi ajustado para 6,0 utilizando solução de hidróxido de sódio a 1 Molar. Após o pH ajustado, adicionou-se 2,4\% de carvão ativado em relação ao volume da solução, e depois foi colocado em um incubador rotativo a velocidade de $200 \mathrm{RPM}$, temperatura de $30^{\circ} \mathrm{C}$ e tempo de 1 hora. O precipitado foi removido através de filtração simples. O hidrolisado foi colocado em autoclave vertical analógica modelo CS 18 durante 15 minutos, $111^{\circ} \mathrm{C}$ e $0,5 \mathrm{ATM}$, evitando que os açúcares fossem consumidos por microrganismos fermentescíveis. (Arruda et al., 2008)

\section{Preparação do inóculo de leveduras e processos fermentativos}

As leveduras de Candida albicans ATCC 10231 foram semeadas em placas de Petri com ágar Sabouraud por 24 horas a $37^{\circ} \mathrm{C}$, após esse tempo as leveduras estavam em quantidade adequada para utilização na fermentação. De acordo com Arruda et al. (2008) para a realização da fermentação utilizou-se o hidrolisado e fez-se 1 inóculo de leveduras com 3 alçadas de 10 microlitros em cada. Posteriormente os erlenmeyers foram submetidos à agitação constante de $150 \mathrm{RPM}$, à temperatura de $30^{\circ} \mathrm{C}$ durante $96 \mathrm{~h}$ em um incubador rotativo. 


\section{Determinação da quantidade de xilitol e xilose}

A concentrações de açúcares e xilitol foram determinadas por equipamentos de Cromatografia Liquida de Alta Eficiência (HPLC) marca Shimadzu nas seguintes condições previamente estabelecidas: coluna Phenomenex Rezex - ROA-Organic Acid $\mathrm{H}+(300 \times 7,8 \mathrm{~mm})$ mantida a $60^{\circ} \mathrm{C}$; detector de índice de refração RID 10A; eluente ácido sulfúrico $5 \mathrm{mM}$, fluxo de $0,6 \mathrm{~mL} / \mathrm{min}$.; volume da amostra injetada, $20 \mu \mathrm{L}$. As amostras foram, previamente, diluídas e filtradas em filtro de seringa PVDF 0,22um de porosidade.

\section{RESULTADOS E DISCUSSÃO}

A figura 01 apresenta o gráfico obtido a partir do leitor de cromatografia líquida (HPLC), na figura observa-se os picos concentração de açúcares obtidos a partir da hidrólise da casca de mandioca, os quais são liberados em determinado tempo em minutos.

A xilose que é o açúcar de maior importância nesse trabalho, obteve $0,27 \mathrm{~g} / \mathrm{L}$ de concentração, outros sacarídeos também foram encontrados como a celobiose com $2,16 \mathrm{~g} / \mathrm{L}$, a glicose com $0,18 \mathrm{~g} / \mathrm{L} \mathrm{e}$ a arabnose com $0,29 \mathrm{~g} / \mathrm{L}$. Não houve presença dos açúcares residuais celulose e hemicelulose. Já que esse trabalho foi o primeiro a relacionar casca de mandioca com a obtenção de xilose, os resultados obtidos são comparados com outras matérias primas.

Uma pesquisa feita com o bagaço da cana e que utilizou uma metodologia semelhante, realizada por Arruda et al. (2008), conseguiu uma concentração de $58 \mathrm{~g} / \mathrm{L}$ de xilose, resultado mais elevado, possivelmente influenciado pelo uso de certos equipamentos como concentrador e filtro a vácuo.

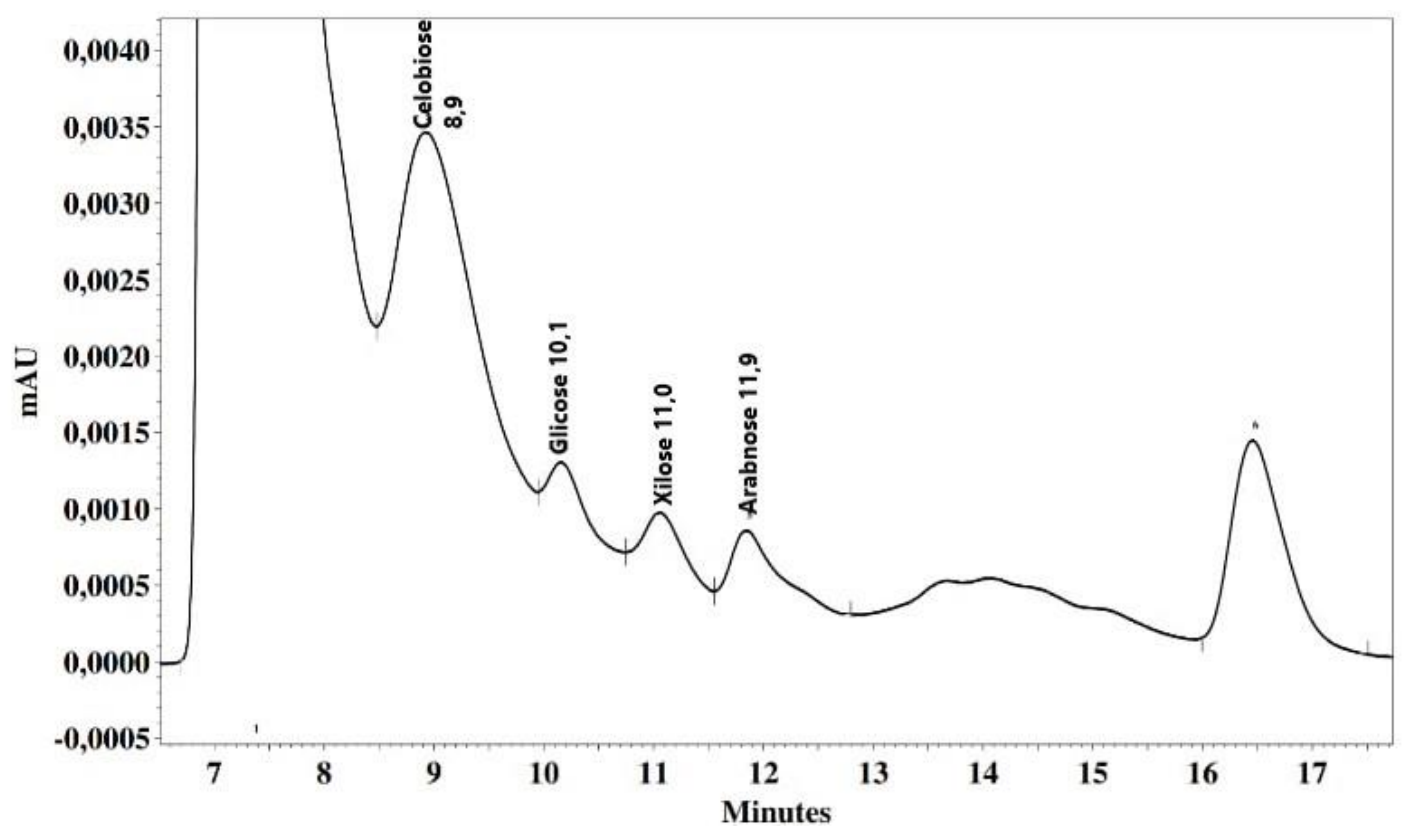

Figura 1 - Picos de concentração de carboidratos gerados pela hidrólise da casca de mandioca.

Conforme estudos realizados por Canettieri (2002), usando cavaco de eucalipto como matéria prima, apresentou a influência do uso de um concentrador à vácuo em sua quantidade final de xilose, antes de usá-lo o hidrolisado apresentou 19,17 g/L e após o uso do concentrador, a concentração de xilose foi para 59,21 g/L, ou seja, o uso do concentrador a vácuo aumentou em 3 vezes a concentração.

De acordo com o trabalho realizado por Mussato et al. (2004) com o bagaço de malte, foram alcançados 19,16 g/L de xilose, essa matéria prima ainda oferece mais xilose do que a casca de mandioca.
Além do uso de equipamentos que auxiliaram na melhora do rendimento, outros motivos que podem explicar a redução do rendimento nesta pesquisa são o tempo de hidrólise e concentração do ácido sulfúrico, já que esse trabalho, seguiu uma metodologia utilizada para obtenção de xilitol a partir do bagaço de cana.

Um trabalho publicado por Cabral et al. (2015), cujo o objetivo era fazer um comparativo entre duas variáveis, tempo de hidrólise e concentração do ácido, para determinar a melhor condição para hidrólise da casca de mandioca, chegou à conclusão de que o ácido a 2\%(v/v) e o tempo de 96 horas são 
as condições ideais que obtiveram as maiores concentrações de açúcares redutores e glicose, a metodologia utilizada obteve como resultado a concentração de 4,4 g/L de glicose e 5,2 g/L de açúcares redutores, contudo não especifica concentração da xilose.

O presente trabalho utilizou condições de hidrólise diferentes, entretanto apresentou resultados mais específicos com a concentração de quatro açúcares, incluindo a xilose que era o açúcar de maior importância nessa pesquisa, contudo devido ao menor rendimento da metodologia aplicada, talvez em outras condições, os resultados seriam melhores, a principal evidencia disso é a concentração de celobiose do presente trabalho, o qual foi o açúcar em maior concentração e que de acordo Knychala et al. (2017) é uma evidencia de hidrólise parcial da celulose, ou seja, o tempo de hidrólise não foi suficiente para quebrar todos os polissacarídeos.

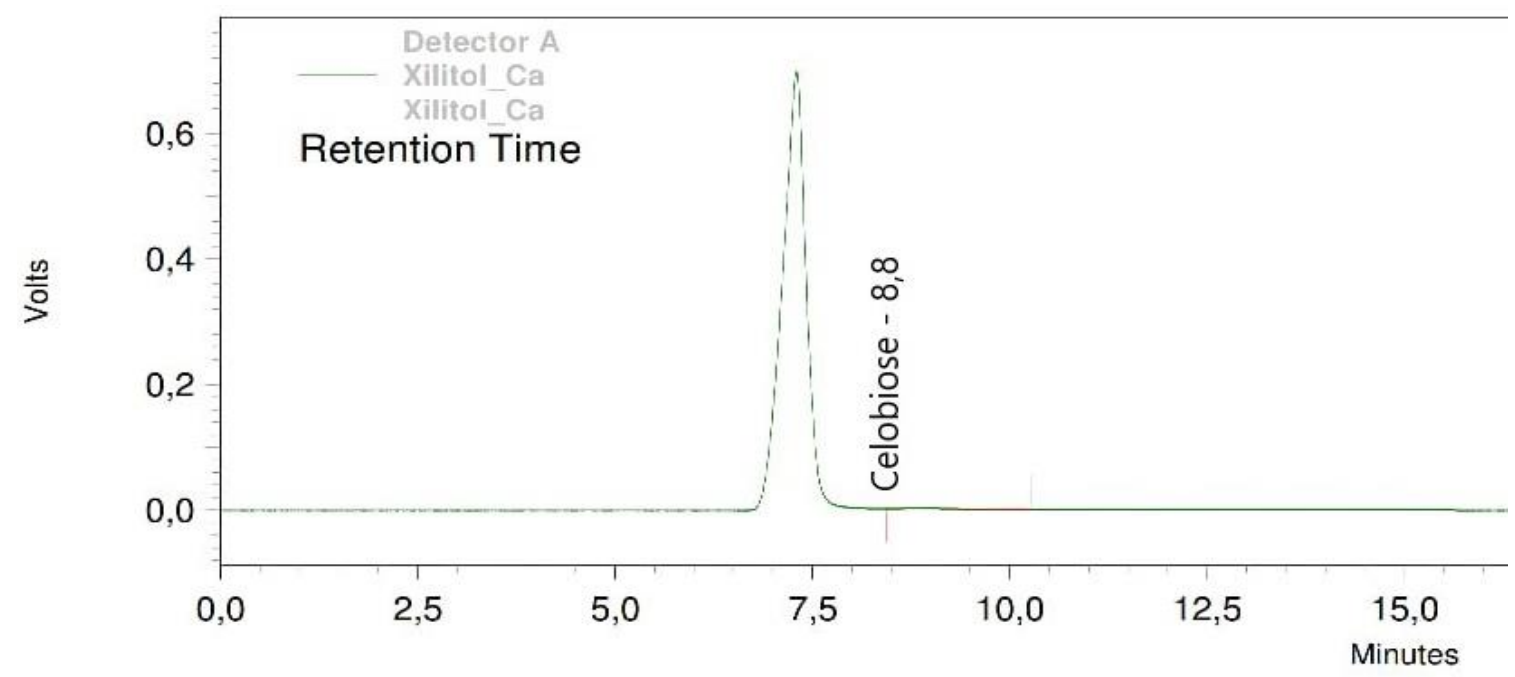

Figura 2 - Picos de concentração de produtos da fermentação a partir do HPLC

Na figura 2 tem-se as concentrações de açúcares após a fermentação por Candida albicans, onde o pico que aparece no gráfico gerado pelo HPLC é do açúcar celobiose que obteve concentração de 2,39 g/L. Já os picos de glicose, xilose e arabnose que apareciam na figura 01, não aparecem mais. A presença desse açúcar e a ausência dos outros demonstra dois resultados importantes, primeiro é que, mesmo sendo mínimos, os açúcares obtidos foram fermentados pela Candida albicans e segundo foi que, a celobiose não é fermentescível por essa levedura.

Após o resultado da hidrólise, a não produção de xilitol em quantidades detectáveis já era esperada já que o trabalho de Mussato et al., (2004) empregou uma concentração de xilose a $50 \mathrm{~g} / \mathrm{l}$ e obteve rendimento de $\mathrm{Y}_{\mathrm{p} / \mathrm{s}}=0,86 \mathrm{~g} / \mathrm{g}$ e produtividade volumétrica de $\mathrm{Q}_{\mathrm{p}}=0,56 \mathrm{~g} / \mathrm{l}$.h, portanto para se ter um rendimento detectável de xilitol teria que ter uma concentração maior de xilose.

Portanto o presente trabalho obteve resultados diferentes dos obtidos a partir de outras matérias primas, entretanto a casca de mandioca possui açúcares fermentescíveis e poderia ser utilizada para obtenção de subprodutos sendo assim o descarte da casca não é a única opção de destinação.

\section{CONCLUSÕES}

A metodologia utilizada no presente trabalho obteve 4 açúcares a partir da casca de mandioca, celobiose, glicose, xilose e arabnose, a concentração de xilose obtida foi de $0,27 \mathrm{~g} / \mathrm{L}$. E também trouxe outros resultados importantes onde, a glicose, xilose e arabnose são fermentescíveis pela Candida albicans e o dissacarídeo celobiose não é. Portanto a casca de mandioca é um subproduto o qual poderia ser utilizado na cadeia produtiva dessa raíz para incrementar lucros e diminuir os impactos ambientais no descarte de resíduos.

\section{REFERÊNCIAS BIBLIOGRÁFICAS}

Cabral A, Ferreira J, Trinca N, Garcia-Cruz CH. Hidrólise da casca de mandioca (manihot esculenta crantz) em diferentes tempos de tratamento e concentrações ácidas para a obtenção de açúcares fermentescíveis. Anais do fórum de iniciação científica do UNIFUNEC, v.6, n.6, 2016.

Canettieri EV, Silva JBA, Felipe MGA. Obtenção biotecnológica de xilitol a partir de cavacos de eucalipto. Revista Brasileira de Ciências Farmacêuticas, v.38, n.3, p.323-331, 2002. https://doi.org/10.1590/S1516-93322002000300008 
Dasgupta D, Bandhu S, Adhikari DK, Ghosh D. Challenges and prospects of xylitol production with whole cell bio-catalysis: A review. Microbiological Research, v.197, p.9-21, 2017. https://doi.org/10.1016/j.micres.2016.12.012

De Brito RS, Brito RS, Moreira VJG, Oliveira AV. Produtividade de mandioca na região do Vale do Juruá, Amazônia Ocidental. Scientia Naturalis, v.1, n.1, p.1-9, 2019.

De Souza RM. Produção de xilitol por linhagens de leveduras do gênero Cyberlindnera. Dissertação de Mestrado - Programa de Pós-graduação em Microbiologia do Instituto de Ciências Biológicas, Universidade Federal de Minas Gerais, Belo Horizonte, 2019.

Dourado DP, Macedo DA, Tonani FL, Muraishi CT. Caracterização bromatológica e classificação da casca da mandioca como fonte para alimentação animal. Revista Integralização Universitária, v.16, n.12, p.22-30, 2017.

Knychala MM. Transporte e fermentação de xilose, celobiose e xilobiose por leveduras Saccharomyces cerevisiae recombinantes. Tese de Doutorado - Programa de Pós-Graduação em Biotecnologia e Biociências da Universidade Federal de Santa Catarina, Florianópolis, 2017.

Kumar V, Sandhu PP, Ahluwalia V, Mishra BB, Yadav SK. Improved upstream processing for detoxification and recovery of xylitol produced from corncob. Bioresour Technol., v.291, p.121931, 2019.

https://doi.org/10.1016/j.biortech.2019.121931

Mussatto SI, Vaz ACS, Roberto IC. Efeito da concentração inicial de xilose na produção de xilitol a partir de hidrolisado de bagaço de malte. VIII Encontro Latino-Americano de Iniciação Científica, São José dos Campos/SP. Anais/CD-ROM de trabalhos completos, p. 527-530, 2004.

Riley M, Locke AB, Skye EP. Health maintenance in schoolaged children: Part II. Counseling recommendations. American family physician, v.83, n.6, p.689-694, 2011.

Ur-Rehman S, Mushtaq Z, Zahoor T, Jamil A, Murtaza M. Xylitol: a review on bioproduction, application, health benefits, and related safety issues. Critical reviews in food science and nutrition, v.55, n.11, p.1514-1528, 2015. https://doi.org/10.1080/10408398.2012.702288.

Yewale T, Panchwagh S, Sawale S, Jain R, Dhamole P. (2017). Xylitol production from non-detoxified and nonsterile lignocellulosic hydrolysate using low-cost industrial media components. 3 Biotech, v.7, n.1, p.68, 2017. https://doi.org/10.1007/s13205-017-0700-2 